\title{
Origens dos empresários da indústria de máquinas e equipamentos em São Paulo, 1870-1900
}

\section{Palavras-chave:}

indústria, máquinas e equipamentos, empresários, São Paulo.

Classificação JEL N66, N76, N86.

\footnotetext{
Key-words

industry, machinery and equipment, entrepreneurs, São Paulo.

JEL Classification N66, N76,
} N86.

\section{Resumo}

O objetivo específico deste artigo é identificar as origens dos empresários, como nacionalidade e gênese do capital para o início $\mathrm{da}$ atividade, na indústria de máquinas e equipamentos em São Paulo, e a evolução do setor no período de 1870 a 1900 . Tentamos identificar os empreendimentos na indústria e sua relação com o comércio importador e exportador, com os fazendeiros de produtos para exportação (principalmente o café), com os imigrantes comerciantes e com os que possuíam algum conhecimento técnico.

\section{Abstract:}

The aim of this paper is to identify the origins of entrepreneurs, such as nationality and the genesis of capital to start the activity in the machinery and equipment industry in Sao Paulo and developments in the sector over the period 1870 to 1900. We will try to identify the entrepreneurs of the industry and its relation to the import and export trade, the farmers of products for export (mainly coffee), immigrants traders and immigrants who have some technical knowledge. 


\section{1_Introdução}

O objetivo geral deste trabalho é descrever o debate da historiografia econômica sobre as origens dos empresários da indústria de máquinas e equipamentos do Brasil, especialmente para a província e depois estado de Sáo Paulo. A origem da indústria de máquinas e equipamentos está diretamente ligada à construção de equipamentos simples e de peças de reposição desses equipamentos. Esse setor começou a ter importância relativa com o desenvolvimento de atividades industriais no final do século XIX. Como o foco econômico nesse período é o desenvolvimento da atividade primário-exportadora, ou seja, a exportaçáo de produtos agrícolas, a indústria como um todo tinha papel subordinado à atividade principal. Assim, o setor industrial era responsável pela produção de bens de consumo, como têxteis e alimentos, e bens de capital, como equipamentos, peças de reposição e máquinas agrícolas simples, responsáveis por aparelhar a atividade principal, o setor primário-exportador.

O objetivo específico desse artigo é identificar as origens dos empresários, como nacionalidade e gênese do capital para o início das atividades na indústria de máquinas e equipamentos, em Sáo Paulo, e a evolução do setor no período de 1870 a 1900. Tentaremos identificar os empreendimentos do setor e sua relação com o comércio importador e exportador, com os fazendeiros de produtos para exportação (principalmente o café), com os imigrantes comerciantes e com os que possuíam algum conhecimento técnico.

$\mathrm{O}$ artigo está divido em mais três seçóes. A próxima seção relata a historiografia econômica sobre as origens da indústria de máquinas e equipamentos em São Paulo, até 1900. A terceira seção apresenta a contribuição empírica para o debate historiográfico, identificando as empresas da indústria de máquinas e equipamentos entre 1873 e 1900 e as origens dos empresários. A última seção resume as principais conclusóes do artigo.

\section{2_A historiografia sobre as origens da indústria de máquinas e equipamentos em São Paulo}

Apesar da indústria de máquinas e equipamentos ter aumentado de importância relativa com o desenvolvimento da economia primário-exportadora a partir de meados do século XIX, antes desse período surgiram algumas iniciativas isoladas no setor. Segundo Luiz Aranha Correa do Lago et alii, no período colonial a principal demanda por equipamentos derivava do aparelhamento de engenhos 
${ }^{1}$ Fato interessante foi o caso da máquina de beneficiar café, inventada em São Paulo pelo mecânico Evaristo Conrado Engelberg, na década de 1880. Engelberg percebeu que o mercado para essa máquina deveria ser o mercado mundial de café e que seria difícil sua produção e distribuição em quantidade no Brasil. Ele vendeu os direitos da máquina a um grupo de norte-americanos que começou a produzi-la em Nova Iorque e a vendê-la em todas as regióes produtoras de café do mundo, inclusive São Paulo, em 1904 (ver DEAN, 1976, p. 18). de açúcar e derivados da cana (LAGO et alii, 1979, p. 6). Em São Paulo houve produção de ferramentas e utensílios em fornos rudimentares já no final do século XVI, mas a despeito da facilidade de aquisição de matérias-primas com a descoberta de minério de ferro, o setor não se desenvolveu. Apenas um pouco antes da Independência, e por iniciativa da Coroa portuguesa, tentou-se a instalação, em São Paulo, de uma indústria de ferro em grande escala, a Fábrica de Ferro Ipanema, implantada em 1810, próxima à Sorocaba (LAGO et alii, 1979, p. 6-7). A Fábrica Real de Ferro de São João do Ipanema, empresa em que a Coroa possuía metade das ações, foi administrada por uma junta de representantes do governo. Sua direção técnica inicial, em 1810, foi dividida entre o mineralogista e metalurgista alemão Friedrich L. Varnhagen e um grupo de técnicos suecos comandados por Carl G. Hedberg. Entre 1815 e 1821 a direção da Fábrica Real ficou sob a responsabilidade de Varnhagen e, com o emprego de escravos e índios, a fábrica produziu ferro em barras, ferro-gusa e obras fundidas. Entre 1835 e 1842 a responsabilidade da direção técnica da Fábrica Real ficou com Bloem, outro técnico alemão, e nesse período foram produzidos implementos agrícolas e canhôes. Depois desse período, a Fábrica
Real viveu uma fase de decadência, sendo reativada durante a Guerra do Paraguai (MOTOYAMA, 2004, p. 154-155).

Apesar da importância da Fábrica Real de Ferro, ela não conseguiu estimular o setor de máquinas e equipamentos em São Paulo, embora tenha produzido alguns implementos agrícolas. Para Roberto Simonsen (1939), a explicação para o não desenvolvimento da indústria siderúrgica no período foi a dependência do combustível e da matéria-prima, o custo do transporte e a baixa demanda pelos produtos: "as grandes distâncias em que se encontravam os nossos minérios, numa época em que os transportes eram dificílimos, e o pequeno consumo que as nossas exploraçóes agrícolas faziam do metal, não estimularam a evolução da nossa indústria siderúrgica” (SIMONSEN, 1939, p. 14).

No final do século XIX havia uma forte ligação entre a economia brasileira com o exterior que favoreceu o surgimento de atividades comerciais de importação e exportação. Essa atividade comercial facilitou a importação de máquinas e equipamentos que não podiam ser fabricados internamente, por falta de conhecimento técnico, de matérias-primas, ou pela dependência em relação ao mercado da Europa e dos Estados Unidos (DEAN, 1976, p. 18). ${ }^{1}$ Dessa forma, 
quase todas as máquinas e equipamentos utilizadas pelo setor primário-exportador, entre meados e a última década do século XIX, eram de origem importada, sendo a atividade local, em sua maior parte, responsável pela reposição das peças simples desses equipamentos. Essa atividade local foi realizada por fundiçóes de origens diversas, oficinas mecânicas ou pelas próprias empresas responsáveis pela comercialização dos equipamentos importados.

O comércio de importação de máquinas e equipamentos, nessa fase inicial do processo de industrialização brasileiro, entre o final do século XIX e início do século XX, não foi obstáculo para o desenvolvimento da indústria como um todo e nem da indústria local de máquinas e equipamentos; pelo contrário, o comércio de importação favoreceu a indústria local, pelo menos em São Paulo. ${ }^{2}$
Três fatores favoreceram o envolvimento de importadores na criação de empresas industriais. $\mathrm{O}$ primeiro foi que, para importar, era necessário determinado número de operaçóes realizadas localmente. A instalação e a manutenção de equipamentos que necessitavam de certa perícia técnica ficavam a cargo do importador e não do comprador, que a princípio não tinha conhecimento específico do equipamento. Assim, o importador de máquinas e equipamentos mantinha muitas vezes uma oficina para a instalação e a manutenção dos equipamentos importados, além do escritório para o comércio de seus produtos (DEAN, 1976, p. 26).

O segundo fator em relação à importância do importador na criação de empresas industriais foi sua posição estratégica no acesso a crédito, mercado e

\footnotetext{
${ }^{2}$ Segundo Dean, em São

Paulo, os importadores, muito mais do que no Rio de Janeiro, tendiam a se transformar em fabricantes. Assim, quando os importadores de Sáo Paulo se voltavam para a indústria, à medida que a atividade de importaçáo se tornava mais difícil, os importadores do Rio de Janeiro se tornavam

novamente simples atacadistas. Wilson Cano argumentou que o Rio de Janeiro apresentou uma das maiores fraçóes do capital mercantil nacional, onde se concentrou o comércio e o financiamento dos principais fluxos mercantis internos e externos. Essa concentração mercantil fez a burguesia reproduzir seu

capital, criando o primeiro espaço industrial significativo do país. Entretanto, a precocidade da implantação industrial e a crise do café no Vale do Paraíba e na Zona da Mata mineira inibiram o desenvolvimento industrial da regiâo frente ao dinamismo do café em São Paulo (CANO, 1985, p. 293-303).
} 
logística. Segundo Dean, todo o financiamento de produtos via crédito era oriundo do exterior. Esse crédito era fornecido por fabricantes e distribuidores europeus ou agências locais de bancos europeus ligados a fabricantes e casas de comércio do exterior. $\mathrm{O}$ crédito fornecido pelos importadores se estendia a atacadistas, lojas do interior e mascates. Os importadores que comercializavam máquinas financiavam tanto os fabricantes como os comerciantes. O aparecimento de empresários fora do ramo de importaçóes era pouco provável, dada a escassez de crédito em outros ramos, e quando eles apareciam ficavam dependentes do importador em relação ao acesso de crédito estrangeiro. $\mathrm{O}$ importador tinha vantagens importantes no conhecimento do mercado. Nem o atacadista, nem outro empresário em potencial tinham o conhecimento do mercado necessário para o cálculo do custo relativo da manufatura nacional, que dependia das oscilações dos direitos aduaneiros e de suas aplicações, e com o qual os importadores, como negociantes, estavam familiarizados. Em relação ao conhecimento da logística do negócio, muitas vezes o importador iniciava sua carreira profissional como mascate e passava a dono de loja do interior, de lojista a atacadista na capital e deste para importador, co- nhecendo assim o negócio desde sua base de distribuição. A distribuição dos produtos do fabricante nacional era realizada tipicamente por meio de importadores, e não através de atacadistas. Os produtores nacionais, geralmente, não tinham as condiçóes necessárias que os importadores possuíam para a realizaçẫo do negócio (DEAN, 1976, p. 27).

$\mathrm{O}$ terceiro fator relativo à posição estratégica do importador como potencial industrial é ilustrado pela quantidade de exemplos de importadores que transformaram suas agências de vendas em fábricas autorizadas. Esse fenômeno foi mais comum em um estágio um pouco mais avançado do processo de industrialização, quando já se necessitava da importação de máquinas complexas que eram protegidas por patentes (DEAN, 1976, p. 28). Nos casos em que os importadores não eram os próprios proprietários industriais, eles agiam como agentes comerciais dos industriais, dada sua disponibilidade de crédito. Para o caso específico do setor de máquinas e equipamentos, Dean apresentou vários exemplos em que o importador diversificou seus produtos conforme a indústria se diversificava. Assim, "acompanhando os progressos do aprimoramento do mercado, importadores como Lion \& Companhia e Mesbla se converteram 
em fornecedores importantes de meios de produção". Outro exemplo é Frederick Upton, imigrante norte-americano que se especializou em manufaturas mais complexas e que, a partir de 1903, passou a vender automóveis, tratores, motores e máquinas agrícolas (DEAN, 1976, p. 36).

Poucos dos primeiros industriais, segundo Dean, parecem não ter começado como importadores, pelo menos no que se refere às firmas maiores e mais importantes. Em relação à indústria de máquinas e equipamentos, há o exemplo de um industrial que não começou como importador: George Graig, mecânico contratado por uma fundição em 1880 e que depois criou sua própria fundição. Contudo, as maiores empresas do setor tinham alguma relação com o comércio de importação: Alexandre Siciliano, que se tornou o maior produtor de máquinas e produtos de metal em todo o estado, havia incorporado a importadora Lacerda Camargo. Dessa forma, os empresários percebiam as funçôes de importador e fabricante como complementares e, mesmo quando se tornavam industriais, continuavam como importadores. Essa complementação de atividades dava-se porque os industriais muitas vezes precisavam de matérias-primas do exterior. Quando não precisavam de matérias-primas, necessitavam de máquinas e equipamentos mais complexos. Ademais, quando importavam eles compravam em quantidade maior do que necessitavam, buscando pagar um preço menor pelo produto importado. Como destacou Dean, "entre a importação por conta própria e a importação para a revenda havia apenas um passo". O importador era, acima de tudo, um negociante que tinha como objetivo o lucro. Quando a atividade de produção abria possibilidades para lucros o importador tornava-se industrial (DEAN, 1976, p. 38).

Outras informaçóes mais detalhadas sobre o comércio de importação e a nascente indústria e máquinas e equipamentos são fornecidas por Lago et alii. Segundo esses autores, em São Paulo, nas três últimas décadas do século XIX, a expansão da cultura do café levou a uma crescente importação de equipamentos para a lavoura e para o beneficiamento agrícola. Essa crescente expansão cafeeira também deu origem ao aparecimento de diversas fundiçóes pelo interior de São Paulo, principalmente na cidade de Campinas, que começaram a produzir implementos agrícolas.

A imigração norte-americana dos anos 1860 para Americana e Santa Bárbara, cidades próximas à regiáo de Campinas, aumentou o uso do arado como instrumento na lavoura, sendo que al- 
guns imigrantes produziam esses implementos (LAGO et alii, 1979, p. 13). Vianna Moog (1954) cita Sérgio Buarque de Holanda ao afirmar que a mecanização da lavoura brasileira não se deveu aos imigrantes norte-americanos, mas que eles foram importantes para o uso de máquinas na lavoura, principalmente o arado. Moog utilizou ainda o trabalho de José Artur Rios para afirmar a importância das realizaçóes desses imigrantes, que produziam seus próprios instrumentos, como é o caso da fábrica de arados de Mark Jefferson, em Santa Bárbara (MOOG, 1954, p. 32).

Além disso, segundo Lago et alii, em 1876 já se produziam em São Paulo, com matérias-primas importadas, máquinas a vapor para descaroçar e enfardar algodão e máquinas para beneficiar café. Na década de 1880, a indústria de São Paulo passou por uma crescente diversificação não apenas no setor de bens de consumo, mas também em bens de capital, na produção de máquinas, apesar da crescente importação. Em meados da década de 1880, os quatro estabelecimentos de fundiçóes de máquinas e aparelhos em Campinas empregavam por volta de 500 operários. Os proprietários desses estabelecimentos eram de origem estrangeira, sendo dois alemães (Faber e Arens), um escocês (Mac Hardy) e um norte-americano (Lidgerwood). Além disso, a capital já contava com cinco fundições em 1887 (LAGO et alii, 1979, p. 16).

Em relação aos estabelecimentos de Campinas, é notória a ligação das empresas da indústria de máquinas e equipamentos com o comércio importador. Os quatro estabelecimentos citados por Lago et alii tinham alguma relação com o comércio importador. A empresa fundada por Johan Ludwig Benjamin Faber, um alemão nascido em Berlim, foi a primeira fundição aberta em Campinas, em 1858, com a denominação de Grande Fundição Brasileira. Faber, que possuía uma fundiçẫo em Berlim, foi convidado a ser mestre de uma grande oficina no Rio de Janeiro, mas quando chegou ao Brasil teve sua expectativa em relação ao trabalho frustrada. Assim, dirigiu-se para a Fazenda Ibicaba, do comendador Vergueiro, em Limeira, e em 1858 foi para Campinas instalar sua fundição. Em Campinas enfrentou dificuldades com relação à matéria-prima, que era toda importada da Alemanha, e com a preferência pelo produto estrangeiro em relaçáo à produção nacional. Em 1878, com o falecimento de Johan, a empresa passou a denominar-se Viúva Faber \& Filhos. Além de importar produtos sob encomenda da Inglaterra, a empresa produzia peças de ferro e bronze para a Compa- 
nhia Paulista de Estradas de Ferro, peças para a infraestrutura de urbanização de cidades, moendas de cana, ventiladores para matar formigas e descascadores para café "Faber". A empresa também fabricava e consertava máquinas para a lavoura e indústria. A empresa acabou encerrando suas atividades por falência em 1909 (CAMILLO, 1998, p. 44-46).

Outra empresa com origem ligada à atividade comercial importadora foi a Lidgerwood. A empresa foi fundada por Guilherme Van Wleck Lidgerwood, um engenheiro mecânico norte-americano estabelecido no Rio de Janeiro desde a década de 1860 que figurava entre os maiores importadores da capital do Império. O estabelecimento da firma em Campinas ocorreu em 1864, e já em 1866 possuía um depósito de máquinas da famosa marca Eagle, em São Paulo. Em 1871, a firma com a denominação Milford \& Lidgerwood foi responsável por assentar e montar as máquinas agrícolas que vendia, além de importar qualquer máquina da Europa. Aparentemente, nesse período a firma teve como principal atividade a importação e o suporte técnico dessas máquinas importadas, não as produzindo ainda. Em 1884, o depósito de máquinas iniciou a produção de máquinas, com a incorporação de oficina mecânica e fundição, necessárias para a manufatura de máquinas. A empresa, além de ser importadora de máquinas, passou a ser também manufatureira, com a denominação Lidgerwood Manufacturing \& Cia. Em 1886, a firma expandiu-se com a instalação de uma nova oficina mecânica, uma grande fundição de ferro e bronze, serraria a vapor, caldeiraria e seçóes de modelagem e serralheria. Um anúncio dessa época mostra que a empresa fabricante e importadora de máquinas comercializava descascadores de café, ventiladores, separadores, despolpadores, catadores, brunidores, moinhos para fubá, engenhos de serra vertical, serras circulares, moendas de cana, alambiques, evaporadores, centrífugas, bombas, vapores fixos e semi-fixos, locomóveis, turbinas de motores, rodas de ferro, motores e todos os utensílios necessários para a montagem de qualquer mecanismo. Em 1889, há registro de depósitos e oficinas da empresa na cidade de São Paulo. No período das epidemias de febre amarela em Campinas, no final dos anos 1880 e início dos anos 1890, Guilherme Lidgerwood não mais residia naquela cidade. A empresa operou até 1922 (CAMILLO, 1998, p. 50-57).

Outro exemplo da relação entre a importação e produção de máquinas foi a firma Arens \& Irmãos. Ela foi constituída por três irmãos (Henrique, Fernando e Augusto Arens), engenheiros mecânicos 
${ }^{3} \mathrm{Na}$ verdade eram duas firmas: a Guilherme Mac Hardy \& Cia., responsável pela seção mecânica, e a Mac Hardy \& Cia. - Fundição Campineira de Ferro e Bronze, responsável pela fundição. formados na Alemanha que, em 1874, estabeleceram-se no Rio de Janeiro como agentes importadores de máquinas para a lavoura e para a indústria. Na tentativa de expansão da empresa, Fernando Arens mudou-se para a província de São Paulo a fim de estabelecer uma filial da empresa. Entre 1875 e 1877 há indícios da fundação, em Campinas, de um "depósito de máquinas importadas" ou de montagem de máquinas, sendo que a produção de máquinas em Campinas por essa firma iniciou-se após 1877. As atividades da firma Arens abrangiam fabricar e assentar máquinas completas, arados e demais implementos para a agricultura. A empresa era o único agente da fábrica de máquinas a vapor Marshall Sons \& Cia. da Inglaterra e também comercializava a "Patent Lombard”, máquina de descascar café para produtores de pequeno porte. A Arens fabricou ainda a máquina Progresso, para o beneficiamento de café, com capacidade de beneficiar de 150 a 200 arrobas de café em dez horas. A máquina Progresso era movida por motor da fábrica inglesa Marshall Sons \& Cia, de 6 HP. Em seus anúncios há indicação ainda de catadores de café, despolpadores, secadores e descascadores cônicos. A empresa de Campinas foi extinta em 1889 devido à epidemia de febre amarela que assolou os negócios da cidade. Em 1890 há indícios de a fir- ma ter sido estabelecida em Jundiaí (CAMILLO, 1998, p. 118-125).

Outra empresa que também possuía relação entre importação e produção de máquinas foi a Companhia Mac Hardy. Essa empresa foi fundada na cidade de Campinas, em 1875, para fabricação de máquinas de beneficiamento de café e ferramentas para a lavoura. Seu fundador, o mecânico Guilherme Mac Hardy, oriundo de Drumblair, na Escócia, chegou em Campinas em 1872 para trabalhar na firma Milford \& Lidgerwood, importadora de máquinas agrícolas. Na década de 1880 a Companhia Mac Hardy ampliou suas instalaçóes e, em 1883, inaugurou novas e grandes oficinas de fundição em duas principais seçôes: ${ }^{3}$ uma de mecânica, em sociedade com John Ross, que veio da Inglaterra a pedido de Guilherme Mac Hardy para ampliar as atividades da empresa; e uma seção de fundição, em sociedade com Joseph James Sims, que residia em Campinas, mas havia trabalhado em fundiçóes londrinas, como a Cadogan Iron Works, e na fundiçẫo dos Hargreaves, no Rio de Janeiro, transferindose para Campinas em 1874 a convite da firma Bierrenbach \& Irmão. A expansão da Companhia Mac Hardy na década de 1880 levou ao aumento da concorrência no mercado de máquinas agrícolas paulista, dado que a Companhia concor- 
ria diretamente com a firma Lidgerwood, grande importadora e fabricante de máquinas agrícolas. $\mathrm{Na}$ seção mecânica da Companhia Mac Hardy produziu-se um tipo de máquina para beneficiar 300 arrobas de café por dia, uma outra (máquina Provincial) que beneficiava de 150 a 200 arrobas de café por dia, além de outras máquinas completas para beneficiar café. A fundição produzia polias, engrenagens, engenhos de cana e turbinas. Em 1889, devido à epidemia de febre amarela que atingiu a cidade de Campinas, os sócios de Guilherme Mac Hardy, Ross e Sims, vieram a falecer. Em 1891, Guilherme Mac Hardy, com apoio de personalidades campineiras, transformou a empresa em sociedade anônima, com a denominação de Companhia Mac Hardy Manufatureira e Importadora. Vários proprietários importantes ligados à política de São Paulo e à agricultura, principalmente a cafeeira, aparecem como dirigentes e acionistas da empresa. Em 1893, Guilherme Mac Hardy voltou para a Escócia, mas mesmo de longe participou da orientação dos rumos da empresa (CAMILLO, 1998, p. 107-113).

Como é possível perceber pela breve exposição da evolução das principais empresas da indústria de máquinas na cidade de Campinas no final do século XIX, os primeiros proprietários foram imigrantes, iniciaram suas ativida- des como importadores de máquinas ou tinham fortes ligações com o comércio importador. Como Dean observou, os importadores foram quase sempre imigrantes e complementaram os fazendeiros no desenvolvimento da indústria paulista (DEAN, 1976, p. 57).

Que os imigrantes foram agentes sociais importantes para a formação industrial e da indústria de máquinas e equipamentos paulista parece ser, então, algo bem estabelecido. Entretanto, há dúvidas quanto à origem desses imigrantes, se iniciaram suas atividades no país como burgueses ligados ao comércio de importação (DEAN, 1976, capítulo IV), se eram imigrantes de classe média (BRESSER PEREIRA, 2002) ou trabalhadores e operários que se tornaram empreendedores (BARBOSA, 2006; BRANDÃO, 2009).

Alguns desses imigrantes estavam ligados ao comércio de importação e, devido às condiçôes favoráveis de sua posição de comerciantes de máquinas em relaçáo a conhecimento do mercado, técnica e de fornecimento de crédito, iniciaram a produção de máquinas e equipamentos no país. Geralmente eram estabelecimentos de grande porte, grandes oficinas ou fundiçóes destinadas no início a reparar as máquinas e que passaram à produção local. O principal trabalho que destacou esse tipo de imigrante 
na formação social da indústria paulista foi o de Dean, como visto.

Entretanto, no final do século XIX e início do século XX, outro tipo de imigrante também foi importante nos empreendimentos industriais em geral e na indústria de máquinas e equipamentos paulista. Eram imigrantes que não possuíam vínculo com o comércio de importação. Especificamente na indústria de máquinas, eles trabalhavam como mecânicos ou técnicos especializados. De modo geral, esses estabelecimentos inicialmente eram de pequeno porte, pequenas oficinas de reparo, que se transformaram em empresas importantes do setor em períodos posteriores.

Luiz Carlos Bresser Pereira realizou uma pesquisa, em 1962, sobre as origens étnicas e sociais de 204 empresários industriais paulistas com mais de cem empregados. Para identificar a origem étnica foi adotado um critério patriarcal, onde o empresário era considerado de origem estrangeira quando o próprio fosse nascido no exterior ou quando o pai ou avô paterno fossem estrangeiros. Para identificar a classe social, o grupo foi dividido em seis classes, onde a mais alta foi identificada à burguesia mercantil que produzia e comercializava o café. As outras classes foram baseadas em informações sobre a situação econômi- ca da família na infância ou adolescência do empresário e em informações sobre a profissão e o nível de educação do pai.

Os resultados da pesquisa sobre as origens étnicas dos empresários paulistas foram que apenas $15,7 \%$ da amostra eram compostos por brasileiros e $84,3 \%$ eram de origem estrangeira (sendo 49,5\% imigrantes, $23,5 \%$ filhos de imigrantes e $11,3 \%$ netos de imigrantes). Quanto à nacionalidade, predominavam empresários de origem italiana $(34,8 \%)$, brasileira $(15,7 \%)$, alemães e austríacos (12,8\%), portugueses $(11,7 \%)$ e árabes (9,8\%). Quanto às origens sociais dos empresários em 1962 apenas 3,9\% eram de famílias ligadas ao comércio e produção de café. Os descendentes de famílias ricas eram $21,6 \%$, enquanto na classe média superior havia 7,8\% dos empresários. As classes médias representaram $50 \%$, enquanto apenas $16,7 \%$ dos empresários originaram-se de famílias pobres. Assim, a conclusão de Bresser Pereira foi que

"os empresários industriais do estado de São Paulo, onde se concentrou a industrialização brasileira, não tiveram origem nas familias ligadas ao café. Originaram-se em familias imigrantes principalmente de classe média" (BRESSER PEREIRA, 2002, p. 146).

Outros estudos abordaram a origem dos empresários industriais em mu- 
nicípios específicos. Agnaldo de Souza Barbosa estudou o processo de industrialização na cidade de Franca de 1920 a 1990 e identificou que os empresários do setor calçadista, o principal setor industrial da cidade, não tiveram sua origem do "vazamento" de capitais da acumulação cafeeira e que, mesmo tendo surgido tardiamente, não necessariamente tinham que nascer grandes (fábricas mecanizadas). As características das empresas encontradas no estudo foram o pequeno porte e a forma de produçâo artesanal. $\mathrm{O}$ autor afirmou que na indústria de calçados em Franca houve a possibilidade de ascensão de pequenos empresários de origem pobre. Esses empreendimentos tiveram origem no ofício manual de seus fundadores, onde artesãos ou operários sapateiros criaram pequenas fábricas. Além de origem humilde, a maioria era de nacionalidade italiana (BARBOSA, 2006, p. 92-110).

Marco Antonio Brandáo encontrou um fenômeno semelhante ao narrado por Barbosa na formação industrial da cidade de Ribeirão Preto, entre 1890 e 1930. Para o autor, a formação do empresariado industrial em Ribeirão Preto se baseou, em sua maioria, em indivíduos carentes de recursos econômicos, já que a constituição de uma pequena empresa não demandava muitos recursos e esses empresários tinham o essencial para a produção: mão de obra familiar ou contratada em pequeno número e o saber fazer necessário. A origem do empresariado industrial em Ribeirão Preto esteve relacionada com imigrantes italianos, trabalhadores pobres que souberam aproveitar as oportunidades, deixando a condição de trabalhadores para tornarem-se empregadores (BRANDÁO, 2009, p. 178-228).

Especificamente para a indústria de máquinas e equipamentos, outros autores notaram a presença do imigrante técnico no contexto da industrialização paulista. Wilson Suzigan observou que

as fábricas que se estabeleceram [na indústria metal-mecânica] antes da guerra produziam especialmente máquinas e implementos agricolas. [...] Algumas das empresas mais novas, [...], além de produzirem máquinas, ferramentas e implementos agricolas, começaram a produção de pequenos tornos. Outras, como a Bardella Indústrias Mecânicas e três outras firmas, iniciaram a produção de máquinas industriais (máquinas para fábricas de papel e papelão e para a indústria de borracha e cerâmica), bombas hidráulicas, pontes rolantes, pequenas turbinas, etc. Praticamente todas essas novas empresas foram fundadas por imigrantes, quase sempre de origem italiana (SUZIGAN, 2000, p. 295). 
$\mathrm{Na}$ mesma linha, Nathaniel Leff afirmou que os imigrantes, geralmente de origem italiana, que chegaram ao Brasil por volta do final do século XIX, foram uma das fontes de empreendedores na indústria de bens de capital. Esses imigrantes trabalharam em estradas de ferro ou em oficinas mecânicas de São Paulo, aprenderam a profissão e acumularam poupança para abrir suas próprias oficinas (LEFF, 1968, p. 16-17).

No período entre as duas guerras mundiais houve declínio de empresas industriais de máquinas e equipamentos ligadas ao comércio importador (comerciante imigrante) e exportador (fazendeiros), e aumento de empreendimentos de imigrantes técnicos mecânicos. Dessa forma, "as adiçóes mais significativas ao parque industrial paulista [no período entre guerras] talvez hajam sido as pequenas oficinas que principiaram a aparecer em setores tecnicamente adiantados da indústria, tais como equipamentos elétricos, máquinas-ferramentas, plásticos e peças de automóveis" (DEAN, 1976, p. 124). Apesar de afirmar que as origens desse novo grupo de empresários eram obscuras, Dean sugere uma generalização a partir de alguns casos e afirma que, de modo geral, "eram membros dos estratos inferiores da classe média, criados na cidade, quase sempre imi- grantes de primeira ou segunda geração, que haviam obtido algum treinamento técnico" (DEAN, 1976, p. 126).

Os imigrantes com conhecimento técnico foram significativamente responsáveis pelos investimentos indiretos externos no século XIX. Artesáos e comerciantes europeus emigravam a fim de abrir negócios próprios com o capital emprestado por seus sócios no país de origem. Neste caso, comprometiam-se a remeter lucros para os pagamentos dos empréstimos e geralmente tinham a intenção de voltar para a Europa quando se aposentassem. A presença desse tipo de empreendimento "era forte, especialmente na fabricação de máquinas e ferramentas e na metalurgia. Por volta de 22 por cento dos investimentos britânicos no exterior, no século XIX, eram feitos por emigrantes" (DEAN, 1983, p. 40-42). Essas companhias fundadas por imigrantes geralmente perdiam sua identificação com o país de origem, naturalizando-se em suas novas regióes.

No setor têxtil, o gênero industrial mais importante do país no período estudado, os imigrantes técnicos foram responsáveis pela instalação e manutenção de máquinas nas fábricas. Segundo Stanley Stein, os fabricantes têxteis brasileiros "dependiam das indústrias de máquinas da Grã-Bretanha, França e Estados Unidos, não só para o equipamento 
como também para os técnicos que vinham supervisionar sua instalação e manutenção" (STEIN, 1979, p. 50). Além de consultores, alguns desses técnicos estrangeiros especializados foram sócios nas fábricas têxteis, facilitando o contato com a indústria de máquinas na Europa e nos Estados Unidos.

Outras fontes de oferta de serviços técnicos especializados e equipamentos para o setor têxtil foram os engenheiros brasileiros, formados em escola técnicas estrangeiras, e as oficinas de reparos das próprias fábricas. Essas duas fontes tornaram a indústria têxtil nacional menos dependente da indústria de máquinas estrangeiras. Os engenheiros brasileiros ligados às fábricas têxteis, geralmente presentes nas duas últimas décadas do século XIX, tinham a tarefa de negociar diretamente com a indústria de máquinas estrangeiras, sem a necessidade de passar por intermediários locais ou "casas de importação", com a finalidade de reduzir o custo de importação do equipamento. Esses técnicos nativos possibilitavam uma escolha melhor em relação ao equipamento têxtil, pois o engenheiro estrangeiro tendia a indicar as máquinas de sua nacionalidade, nem sempre as de maior custo-benefício. As oficinas de reparos fabricavam peças de reposição para as dispendiosas máquinas têxteis. Os empresários locais diminuíram sua dependência em relação à indústria de máquinas estrangeiras, economizando mais tempo do que dinheiro. Os empresários têxteis tinham problemas com o atraso na entrega dos equipamentos, e em relação às informações sobre as máquinas. A oficina mecânica dentro da fábrica diminuía a anomalia de manter uma indústria têxtil algodoeira sem uma indústria nacional de máquinas têxteis. Apesar desses avanços na tentativa de diminuir a dependência da indústria de máquinas estrangeiras, "a instalação das máquinas continuou a ser, na maioria dos casos, uma tarefa reservada a trabalhadores especializados estrangeiros, sob a supervisão técnica dos montadores ingleses ou americanos" (STEIN, 1979, p. 52).

Apesar da gênese da indústria mecânica em São Paulo ter forte ligaçáo com o empreendedor imigrante, seja ele o comerciante importador e depois produtor de máquinas e equipamentos, ou ainda o imigrante técnico mecânico de classe média ou baixa, havia outros agentes sociais responsáveis pelo desenvolvimento e expansão da indústria mecânica. As fontes de demanda por máquinas e equipamentos até a segunda década do século XX estavam atreladas à lógica de uma economia primário-exportadora. Conforme notado por Leff, foram várias 
as fontes de demanda por produtos mecânicos: a) a economia agrícola exportadora necessitava de infraestrutura de transportes que requeria serviços de manutenção e reparação de peças, primeiramente material ferroviário e, mais tarde, rodoviário. Esse tipo de serviço necessitava ser realizado no local devido a prazos imediatos de atendimento; b) a economia agrícola exportadora necessitava beneficiar os produtos de exportaçáo, sendo os equipamentos de processamento e beneficiamento de café, açúcar e algodão os primeiros entre os produtos mecânicos introduzidos na economia brasileira; c) outros usuários e consumidores de produtos mecânicos foram as forças militares para reparação e construçấo de peças de equipamentos; d) equipamentos para a indústria de construção foram demandados especialmente para a construção da infraestrutura necessária para o comércio exterior (LEFF, 1968, p. 9).

Assim, além de representar as principais fontes de demanda para a indústria mecânica, o setor primário-exportador também forneceu recursos para a expansão e o desenvolvimento da indústria de máquinas e equipamentos. Com a finalidade de diversificar seus investimentos, ou mesmo a necessidade de amparar sua principal atividade econômica beneficiando produtos agrícolas, os fazendeiros participaram do investimento na indústria e, também, na indústria de máquinas. A escassez de mão de obra estimulou o uso de máquinas capazes de realizarem o processo de beneficiamento do café. Apesar de serem imigrantes os mecânicos que aperfeiçoaram esses equipamentos,

"a iniciativa e o capital que escoravam as oficinas eram [de fazendeiros] paulistas. Essas mesmas oficinas produziram grande variedade de equipamento modelado e usinado, principalmente para o uso nas fazendas e estradas de ferro, como caldeiras, bombas, vagóes fechados de carga e artigos semelhantes" (DEAN, 1976, p. 44).

Da mesma forma, Dean observou que os próprios agricultores investiram em atividades como a produção de ferro e aço, que empregavam matéria-prima importada, pois "tais companhias produziam máquinas e obras de fundição que ficariam mais caras se fossem compradas no exterior" (DEAN, 1976, p. 77).

É interessante notar que a elite de fazendeiros parece ter absorvido alguns imigrantes por meio de alianças familiares, pelo casamento. $\mathrm{O}$ caso mais importante desse tipo de aliança entre fazendeiros e imigrantes vincula-se à história da principal empresa produtora de máquinas do estado de São Paulo no início do 
século XX, a Cia. Mecânica Importadora de São Paulo. Segundo Dean, Alexandre Siciliano foi talvez o industrial imigrante que tinha melhores conexóes com empresas agrícolas. Siciliano chegou a São Paulo em 1869, com nove anos de idade, e começou a trabalhar em uma casa de comércio em Piracicaba, de propriedade de um tio e um irmão mais velho que o haviam precedido na migração. Em 1881 casou com Laura Augusta de Mello Coelho, filha de um fazendeiro rico e influente. Logo depois, Alexandre Siciliano começou a produzir máquinas de beneficiar café em sociedade com o irmão, Francesco, e com João Conrado Engelberg, inventor da máquina. A patente dessa máquina foi vendida nos Estados Unidos e, depois disso, Alexandre Siciliano mudou-se para a capital do estado, participando da fundação de um banco, de uma casa importadora de e uma oficina mecânica e de fundição. A oficina mecânica e de fundição foi a Companhia Mecânica e Importadora de São Paulo, na qual Siciliano tornou-se presidente. A Companhia Mecânica incluía uma fundição, seção de máquinas, serraria, carpintaria e olaria, produzindo vagóes de estrada de ferro e máquinas agrícolas, principalmente de beneficiamento. O capital da firma proveio de uma parte dos lucros da empresa de Piracicaba e da venda das patentes, mas a maior parte teria sido de contribuiçóes de fazendeiros que eram agora seus parentes. $\mathrm{O}$ empreendimento prosperou com a influência dos maiores fazendeiros do estado como diretores da empresa. Aos poucos, Siciliano comprou as partes dos sócios fazendeiros e acabou tornando-se o único dono (DEAN, 1976, p.82-83).

Assim, podemos identificar várias fontes de capital para a indústria de máquinas e equipamentos na historiografia econômica: os comerciantes e técnicos imigrantes, os fazendeiros e a união desses grupos.

\section{3_ A indústria de máquinas e equipamentos em São Paulo, 1870-1900}

O objetivo desta seção é contribuir com a historiografia econômica sobre a indústria de máquinas e equipamentos entre 1870 e 1900. Foi realizado um trabalho de coleta e sistematização das informações quantitativas e qualitativas disponíveis para a indústria de máquinas e equipamentos paulista. Outro esforço realizado foi no sentido de corrigir os erros e lacunas nos dados estatísticos anteriores a 1920, ano do primeiro Censo Industrial do Brasil, com grande quantidade de outras fontes publicadas pos- 
teriormente, mas que apresentavam informações de fundaçóes de empresas no período anterior a 1900. Assim, esta seção utiliza como principais fontes: a) o Almanak da Província de São Paulo para 1873; b) o Almanach do Estado de São Paulo para 1891; c) a Indústria no Estado de São Paulo em 1901, de Bandeira Jr.; d) o Inquérito Industrial do Brasil de 1907, do Centro Industrial do Brasil; e) a Estatística Industrial de São Paulo de 19181919 (municípios do interior), publicada no Boletim da Diretoria da Indústria e Comércio, da Secretaria da Agricultura, Comércio e Obras Públicas de São Paulo entre 1918 e 1922; f) o Catálogo das Indústrias do Município da Capital e Interior, de 1945; g) o Anuário Banas: a indústria brasileira de máquinas, de 1962; e várias outras fontes qualitativas.

\section{1_Origens dos empresários}

É impossível precisar uma data para o surgimento das primeiras indústrias de máquinas e equipamentos em São Paulo. É provável, como discutido na seção anterior, que desde o período colonial já se produzisse ou realizasse a manutenção de algumas máquinas rudimentares nessa região. Entretanto, parece ser indiscutível que o ramo industrial e o próprio processo de industrialização começaram a se desenvolver com o cresci- mento econômico proporcionado pela expansão agro-exportadora na segunda metade do século XIX. Nesta seção buscaremos entender a origem dos empresários da indústria de máquinas e equipamentos no final do século XIX e início do século XX. Nesta seção identificaremos quem eram os empreendedores do setor e qual sua relação com o comércio exterior, com os fazendeiros e com os imigrantes entre 1870 e 1900.

As características das empresas da indústria de máquinas e equipamentos na província de São Paulo, em 1873, são apresentadas no Quadro 1. As empresas que produziam máquinas nesse período, em sua maioria, faziam parte de um núcleo urbano artesanal. A maioria dos produtores fazia parte de alguma ocupação artesanal do local onde estavam situados, como torneiro, carpinteiro, ferreiro, marceneiro, maquinista, entre outras. Alguns desses produtores eram artesãos de origem germânica, parte da primeira imigração europeia iniciada na década de 1840, anterior à "imigração em massa" na década de 1880 . Havia pouca relação desses produtores com o comércio importador e com fazendeiros. Foi possível catalogar apenas um importador (Haupt $\&$ Cia.) e um fazendeiro (Antonio Carlos Sampaio Peixoto) que também eram produtores de máquinas e equipamentos. 
Vejamos algumas informaçóes de empresas que aparecem no quadro. George Hunde foi um artesão que possuía uma fábrica e oficina mecânica na Rua da Estação, Santa Ifigênia, em São Paulo, em 1871. Sua firma possuía uma fundição, um guindaste e um torno mecânico, entre outros equipamentos (MADURO JR; MARCONDES, 2005, p. 11). Em Pinda- monhangaba, Antonio Fernandes Vianna fabricava máquinas para lavoura, além de ser torneiro de madeira. Em 1879, Antonio registrou a patente da máquina agrícola chamada "Brunidor Paulista". Benedito Silvério da Silva e Nicolao Estrubim aparecem também como carpinteiros, além de construtores de máquinas agrícolas (LUNÉ, 1985, p. 139).

\section{Quadro 1_Empresas de máquinas, oficinas mecânicas e fundições, província de São Paulo, 1873}

\begin{tabular}{|c|c|c|}
\hline Empresas & Cidade & Atividades \\
\hline George Hunde & São Paulo & fundição e oficina mecânica \\
\hline Antonio Fernandes Vianna & Pindamonhangaba & fábrica de máquinas para lavoura \\
\hline Benedito Silvério da Silva & Pindamonhangaba & fábrica de máquinas para lavoura \\
\hline Nicolao Estrubim & Pindamonhangaba & fábrica de máquinas para lavoura \\
\hline Pedro Antonio de Alcantara & Pindamonhangaba & fábrica de máquinas para lavoura \\
\hline Antonio C. Sampaio Peixoto & Campinas & máquinas de beneficiar café e fundiçáo \\
\hline Bierrembach \& Irmáos & Campinas & máquinas de beneficiar café e fundição \\
\hline Francisco Walter Muller & Campinas & ventiladores para café \\
\hline Guilherme Zichel & Campinas & fundição de metais \\
\hline Luiz Faber & Campinas & fundição de metais \\
\hline Felippe Leonardo & Rio Claro & fábrica de máquinas e fundição \\
\hline Jeorge Petri & Rio Claro & fábrica de máquinas e fundição \\
\hline João Henrique Reiff & Rio Claro & fábrica de máquinas e fundição \\
\hline Samuel Kreiner & Rio Claro & fábrica de máquinas e fundição \\
\hline Haupt \& Cia. & Sáo Paulo & importador, bombas hidráulicas \\
\hline
\end{tabular}


Em Campinas, Antonio Carlos Sampaio Peixoto, de nacionalidade brasileira e fazendeiro, havia fundado entre 1867 e 1868 uma olaria, uma ferraria, uma fundição de ferro e uma oficina mecânica. A oficina mecânica produziu máquinas para beneficiar café, engenhos completos para moer cana, peças de tornos, transmissóes, parafusos e ferragens para carros. No início dos anos 1870, a ferraria, fundição e oficina mecânica empregavam 22 artesãos. Ainda assim, a principal atividade da firma de Antonio Carlos Sampaio Peixoto parece ter sido a olaria. Em 1875, possivelmente a única atividade da firma foi a fabricação de tijolos pela olaria. Em 1879, Sampaio mudou-se para Limeira para administrar uma fazenda de seu pai, sendo que a olaria voltou a funcionar entre 1882 e 1886 sob a administração de Joaquim Olavo de Sampaio, filho de Antonio Carlos (CAMILLO, 1998, p.66-69). Em Rio Claro, Felippe Leonardo, Jeorge Petri, João Henrique Reiff e Samuel Kreiner exerciam a profissão de maquinistas e possuíam fábricas de máquinas em 1873 (LUNÉ, 1985, p. 515).

As empresas construtoras de máquinas para a lavoura e indústria, fundiçôes e oficinas mecânicas no estado de São Paulo, em 1891, estão listadas no Quadro 2.
A primeira observação importante a ser feita é o fato de já em 1891 existirem várias empresas produtoras de máquinas e equipamentos, mesmo sem evidência de proteção tarifária, já que a importação de "máquinas para lavrar a terra e preparar produtos para a agricultura, mineração, serviços de qualquer fábrica ou oficina", assim como "locomotivas", possuía isenção tarifária em 1890 (BRASIL, 1890, p. 123).

Há uma mudança significativa na indústria em 1891 em relação a 1873, devido ao crescimento do comércio internacional nesse período. Várias dessas empresas, além de fabricarem máquinas e peças para reposição das máquinas e prestarem reparos nas oficinas mecânicas, eram também casas de importação e ou de exportação pertencentes a imigrantes. Os proprietários estrangeiros possuíam acesso a empresas produtoras no exterior para a importação de alguma máquina, como o caso da Arens, que foi agente de representação da fábrica de máquinas Marshall Sons \& C. da Inglaterra, e a crédito de bancos estrangeiros. Das 21 empresas que foram identificadas na indústria de máquinas, oficinas mecânicas e fundiçôes em 1891, 10 tinham alguma relação com o comércio internacional, conforme pode ser identificado na própria fonte (Almanach de 1891) e 
Quadro 2_Empresas de máquinas, oficinas mecânicas e fundições, estado de São Paulo, 1891

\begin{tabular}{|c|c|c|c|}
\hline Empresas & Cidade & Atividades & Nacionalidade \\
\hline Adolpho Sydow & São Paulo & construtores de máquinas & alemã \\
\hline Elias Pacheco Chaves & São Paulo & máquinas para lavoura e indústria & brasileira \\
\hline Frederico Sydow & São Paulo & construtores de máquinas & alemá \\
\hline Hasenclever \& Comp. & São Paulo & $\begin{array}{l}\text { material para estrada ferro, máquinas e casa de } \\
\text { importação }\end{array}$ & alemã \\
\hline John Muller \& Comp. & São Paulo & máquinas e casa de importação & \\
\hline J. P. de Castro \& Comp. & São Paulo & máquinas e casa de importação & \\
\hline Cia Mechanica e Importadora & Sáo Paulo & construtores de máquinas e importação & \\
\hline Lidgerwood \& Comp. & São Paulo & construtores de máquinas e importação & americana \\
\hline Roquette, Franco \& Barros & São Paulo & máquinas para lavoura e indústria & \\
\hline Zerrenner \& Bullow & São Paulo & máquinas e casa de importação & alemã e dinamarquesa \\
\hline E. Heinke \& C. & São Paulo & oficina mecânica & \\
\hline Salles, Leme, Faber \& Comp. & Campinas & fundição e fábrica de máquinas & alemã (parte) \\
\hline Francisco de Góes Pacheco & Campinas & fundição e fábrica de máquinas & \\
\hline Oliveira Costa \& Comp. & Campinas & fundição e fábrica de máquinas & \\
\hline Lidgerwood \& Comp. & Campinas & fundição, fábrica de máquinas e importadora & americana \\
\hline $\begin{array}{l}\text { Guilherme Mac Hardy \& } \\
\text { Comp. }\end{array}$ & Campinas & fundição, fábrica de máquinas e importadora & britânica \\
\hline Pedro A. Anderson \& Comp. & Campinas & $\begin{array}{l}\text { fundição, fábrica de máquinas, importadora e } \\
\text { exportadora }\end{array}$ & \\
\hline Arens Irmãos & Jundiaí & fundição, oficina mecânica e importadora & alemá \\
\hline Vicente Mariano \& Irmão & Mococa & oficina mecânica & \\
\hline Lidgerwood Mfg. Comp. Ltd. & Santos & máquinas para lavoura e importadora & americana \\
\hline Arminio V. Lessa Pabest & Santos & oficina mecânica & \\
\hline Haupt \& Cia. & São Paulo & importadora, bombas hidráulicas & \\
\hline J. Nicola \& Irmãos & Mococa & $\ldots \ldots \ldots$ máquinas agrícolas $\ldots \ldots \ldots$ & italiana \\
\hline
\end{tabular}


em anúncios de jornais da época. Mas é possível que outras também tivessem a mesma relação.

Aparecem como produtoras de máquinas para a lavoura e a indústria, e também como casas de importação, no Almanach de 1891, as empresas John Muller \& Comp., J. P. de Castro \& Comp., Zerrenner \& Bullow \& Comp., Pedro A. Anderson $\&$ Comp. (que aparece em um anúncio como casa de importação, exportação, comissões e fundição e fábrica de máquinas para a lavoura, arados, bombas, carroças e etc.) e a Hasenclever \& Comp. (que aparece em um anúncio como agente de importação de trilhos de aço portáteis e fixos, vagóes para todos os fins, locomotivas e locomóveis, linhas férreas com tração a vapor ou animal, bondes de passageiros e de cargas, máquinas para olarias e outras indústrias e máquinas para engenhos de cana) (SÃO PAULO, 1891, p. 303, 298, 48, 68). A Cia. Mecânica Importadora de São Paulo, fundada em 1890 e sucessora das empresas Lacerda Camargo \& Comp. (uma empresa importante de importação) e da Engelberg, Siciliano \& Comp., apresentou como especialidade em um anúncio a importação direta de máquinas para todas as indústrias, além de ser construtora de máquinas e fundição (SÃO PAULO, 1891, p. 236). As empresas Lidgerwood, Gui- lherme Mac Hardy e Arens Irmãos fizeram vários anúncios, como "construtores, empresários, engenheiros, fabricantes e importadores de máquinas para a lavoura e indústria”, em jornais de Campinas (Diário, Correio e Gazeta de Campinas), entre o final da década de 1880 e o início de 1890. A firma Haupt \& Cia., apesar de não constar no Almanach de 1891, foi fundada em 1823 (segundo o Anuário Banas de 1962) e produzia bombas hidráulicas (segundo o Catálogo de Indústrias do Município da Capital de 1945), além de ter sido uma importante importadora de artigos metalúrgicos (DEAN, 1976, p. 33).

É importante ressaltar que em 1891 as empresas já haviam ultrapassado o estágio de meros reparadores de máquinas importadas. Muitas das empresas já apareciam em anúncios de jornais como "fabricantes e importadores", principalmente de máquinas agrícolas. Há no Almanach de 1891 uma grande quantidade de ferreiros, serralheiros e mecânicos individuais na capital e no interior do estado de São Paulo, mas é difícil afirmar se estavam ligados à produção de máquinas, apesar de provavelmente terem sido importantes no reparo de algumas delas (SÃO PAULO, 1891, p. 293).

Os imigrantes alemães predominaram como proprietários de empresas de máquinas e equipamentos nos anos 
1890. A família Sydow veio da Alemanha por volta de 1859 e fundou na cidade de São Paulo a primeira serraria a vapor local. Os irmáos Frederico e Adolfo adquiriram fazendas em Xiririca (atual Eldorado). Na década de 1870, Adolfo já tinha expressão como industrial, fabricando máquinas e equipamentos para a agricultura. Frederico participou como administrador, entre 1899 e 1900, da reforma da Usina Elétrica de Rio Claro, empreendimento organizado por Theodor Wille \& Cia., importante empresa de Hamburgo que tinha entre suas atividades a produção e exportação de café, importação de máquinas, financiamento de usinas hidroelétricas e numerosas fábricas. Theodor Wille havia adquirido a Usina de Fernando Arens, engenheiro e industrial da Casa Arens \& Irmãos (SANTOS, 2002, p. 142-143).

Outro empreendimento em parte de capital alemão ligado à indústria de máquinas foi a firma Zerrenner $\&$ Bullow \& Comp. Essa empresa, além de aparecer como construtora de máquinas, também aparece como casa de importação, banco de câmbio (cambista), depósito de querosene, entre outros. João Carlos Antônio Zerrener e Adam Ditrik Von Bullow, proprietários da Zerrenner \& Bullow \& Comp., foram sócios minoritários da Companhia Antarctica Paulista, fábrica de cerveja na Avenida Água Branca, constituída em 9 de fevereiro de 1891, com um capital de 3.000 contos de réis. A função deles na Antarctica foi facilitar a compra de máquinas no exterior e obtenção de créditos junto a bancos estrangeiros, já que era prática comum a participação de importadores nas fábricas que surgiram no Brasil, no período, com essa finalidade. Em 1893, a Antarctica estava próxima da insolvência, passando por dificuldades cambiais e atrasos em navios que traziam máquinas. A firma Zerrenner \& Bullow \& Comp., que possuía direitos a receber da Antarctica no valor de 860 mil-réis, assumiu o controle acionário da Antarctica com 51,15\% do capital, depois de um acerto de contas que reduziu o capital da empresa em 1.710 contos de réis. A importadora Zerrenner \& Bullow \& Comp., além de ser responsável pelas máquinas, também distribuía os produtos da Antarctica. Adam Ditrik von Bullow morreu em 1923, com 80 anos, deixando seu filho Carl Adolf como seu representante no comando da empresa. Em 1929, a sociedade dos Zerrenner e dos Bullow operava com importação, bebidas (na Antarctica) e exportação de café (com a Companhia Cafeeira de São Paulo, recém-criada). Antônio Zerrener morreu em 1933, sem herdeiros, deixando em testamento seus bens para 
sua esposa Helena, os quais, depois da morte desta última, que ocorreu em 1936, deveriam ir para a Fundação Antônio e Helena Zerrener. A fundação passou a administrar os bens da Antarctica, como maior acionista, em 1944, após um período de litígio judicial para resolver a questão da herança de Antônio Zerrener (EXAME, 1974, p. 51-54).

Ao analisar os dados disponíveis, encontramos apenas uma empresa de máquinas e equipamentos, em 1891, ligada diretamente a fazendeiros de café, a firma de Elias Pacheco Chaves, que tinha como esposa Anésia da Silva Prado, representantes, portanto, de antigas famílias de cafeicultores. É possível que existissem outras empresas ligadas aos cafeicultores nessa época, mas é improvável que fossem predominantes. Apesar de serem raras as empresas da indústria mecânica que tiveram ligação direta com os cafeicultores, o capital destes últimos foi importante para a expansão das empresas de máquinas e equipamentos, principalmente após 1891, com a transformaçâo de algumas empresas pertencentes a imigrantes em sociedade anônima, como a Mac Hardy e a Arens. No caso da Arens, há um anúncio no Almanach de 1891 descrevendo a aquisição das oficinas Arens e Irmãos pela Companhia Arens, empresa com capital de 2.000:000\$000 (dois mil contos de réis) divididos em dez mil ações, tendo como presidente o Barão de Jaguara, secretário Antonio de Paula Salles e gerente Otto Schanassmann, ficando um representante da família Arens no conselho fiscal composto por Carlos H. L. Rohe, Fernando Arens e Francisco de Araújo Cintra (SÃO PAULO, 1981, p. 794). Segundo Flávio Saes, os principais acionistas da empresa (A. Pádua Sales, José Paulino Nogueira, Pedro Souza Aranha, F. Queiroz Telez) eram fazendeiros de café ligados à Companhia Estrada de Ferro Mogiana (SAES, 2002, p. 189). As firmas Guilherme Mac Hardy \& C. e Guilherme Mc-Hardy de Campinas passam a denominar-se, em 1891, Companhia Mc-Hardy Manufatureira e Importadora, sociedade anônima que tinha como objetivo atuar no que estivesse relacionado com a fabricação, construção e importação de máquinas, materiais para estrada de ferro, para abastecimento de água e dependência para iluminação, importação em geral e empreitadas, exploração de privilégios, concessóes e contratos, fornecimentos para construçóes civis, navais e hidráulicas, além de adquirir, vender e fundar fábricas, fazer instalaçóes, podendo explorá-las, arrendar ou vendê-las (CIA. MC-HARDY, 1891, p. 3-4). A nova empresa foi constituída com um capital social de quatro mil contos de réis, 
dividido em 20 mil açóes. A primeira diretoria foi composta pelo fazendeiro Barão de Ataliba Nogueira, pelo industrial Guilherme Mc-Hardy e pelo advogado Gabriel Dias da Silva, todos residentes em Campinas. O conselho fiscal foi composto por Roberto Paton, Pedro Miller e Antonio Celestino de Toledo Soares (CIA. MC-HARDY, 1891, p. 5, 15-16). Em 1893, no lugar do diretor gerente Guilherme Mc-Hardy, que permanecia na Europa, a princípio a serviço da Companhia e em seguida por motivos de saúde, foi nomeado gerente o acionista Roberto Paton. No conselho fiscal, devido ao falecimento de Pedro Miller, ocupou seu lugar o suplente Roberto Clark. Assinaram o estatuto da companhia, em 1893, Gabriel Dias da Silva, como diretor da Companhia, e o Barão de Ataliba Nogueira, como presidente (CIA. MC-HARDY, 1893, p. 6-8).

É interessante observar que entre os acionistas da Companhia Mc-Hardy Manufatureira e Importadora, em 1893, aparecem vários empresários, imigrantes, fazendeiros de café e políticos importantes da cidade de Campinas e do estado de São Paulo, além dos dirigentes da empresa citados acima. Fazem parte da lista de acionistas: Antonio Proost Rodovalho, João Proost Rodovalho, Sotto Maior, John Barker, Orozimbo Maia, Manoel J. Albuquerque Lins, Francisco
Goes Pacheco, entre outros, de um total de 113 acionistas e 20 mil açóes em 1893. Os maiores acionistas da Mc-Hardy em 1893 foram: o Banco dos Lavradores com 27,9\% do total de açóes, Guilherme Mc Hardy com 25,2\%, Gabriel Dias da Silva com 3,2\%, Roberto S. Paton, com 2\% e o Barão de Ataliba Nogueira com 2\% das açōes (CIA. MC-HARDY, 1893, p. 11-17). Segundo Saes, o Banco dos Lavradores estava ligado a fazendeiros de café, que mantinham vínculos com as estradas de ferro e com empresas de serviço público (SAES, 2002, p. 189).

O Quadro 3 apresenta informações das empresas de máquinas, oficinas mecânicas e fundiçóes operando no estado de São Paulo, em 1901. A principal fonte para o período, "A indústria no estado de São Paulo, 1901”, de Antonio Francisco Bandeira Jr., como já notado, não foi um levantamento completo. O Quadro 3 foi elaborado com o objetivo de amenizar esses problemas, cruzando informações de várias fontes em anos posteriores que apresentavam datas de fundação para as empresas, as quais sáo indicadas no quadro. Apesar dos complementos, o quadro também não pode ser utilizado como um censo das empresas que produziam máquinas e equipamentos em 1901 porque certamente também não está completo, a despeito de todo o esforço que fizemos pa- 
Quadro 3_Empresas de máquinas, oficinas mecânicas e fundições, estado de São Paulo, 1901

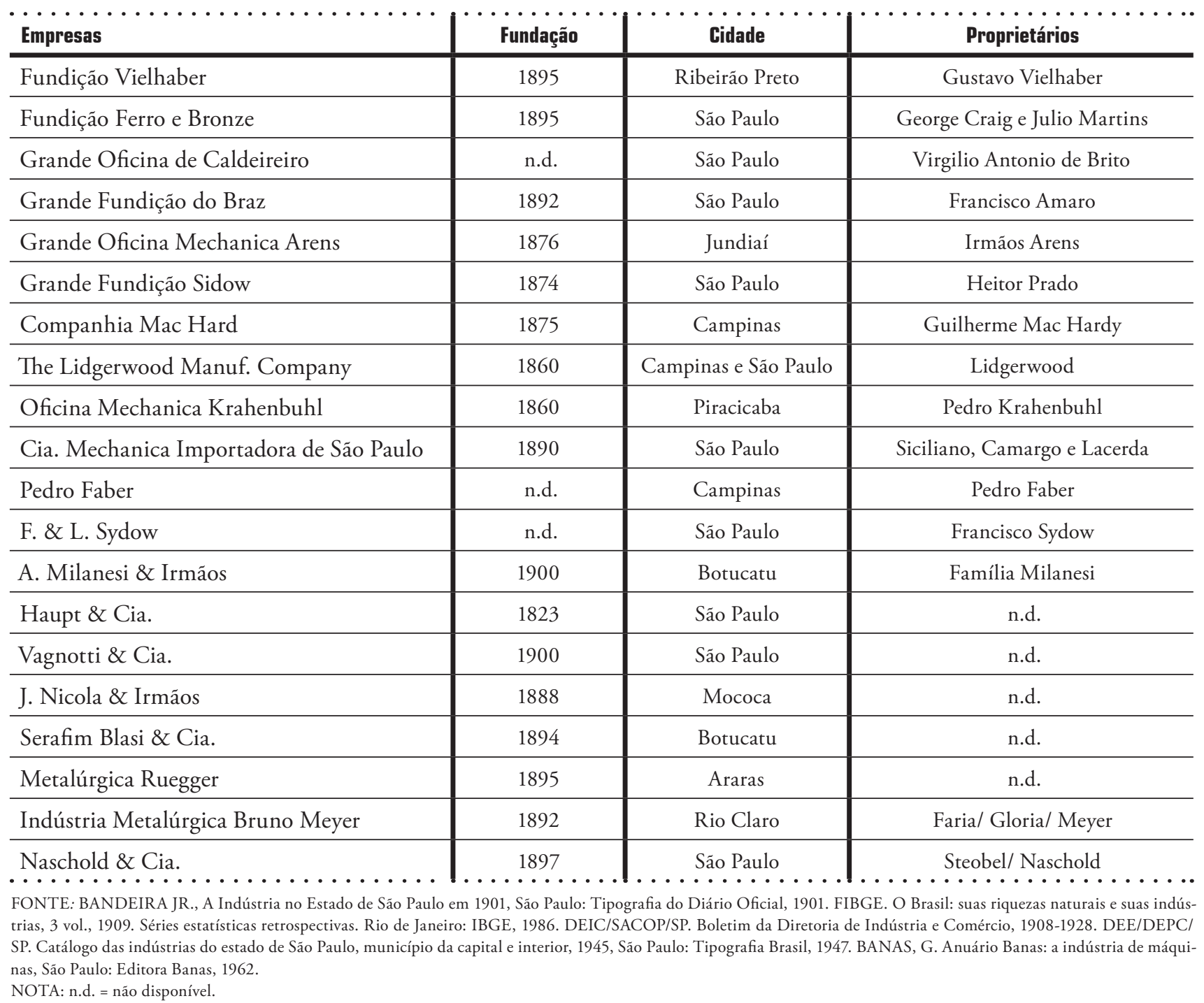


ra coletar fontes com informaçóes de empresas e suas datas de fundação.

A primeira informação que podemos extrair do Quadro 3 é o maior número de empresas ligadas à indústria de máquinas, oficinas mecânicas e fundiçóes no estado de São Paulo fundadas entre 1891 e 1900. Das 20 empresas apresentadas no quadro, 9 foram fundadas entre 1891 e 1900: a Indústria Metalúrgica Bruno Meyer (1892), em Rio Claro; a Grande Fundição do Braz (1892), de Francisco Amaro, em São Paulo; a Serafim Blasi (1894), em Botucatu; a Metalúrgica Ruegger (1895), em Araras; a Fundição Vielhaber (1895), em Ribeirão Preto; a Fundição de Ferro e Bronze (1895), de George Craig e Julio Martins, em São Paulo; Naschold \& Cia. (1897), em São Paulo; A. Milanesi \& Irmãos (1900), em Botucatu; e a Vagnotti \& Cia. (1900), em São Paulo. Há também diversificação das empresas pelo interior do estado de Sáo Paulo. Na maioria, as empresas fundadas entre 1891 e 1900 tiveram origem em imigrantes que possuíam algum conhecimento técnico de mecânica ou metalurgia.

A Metalúrgica Ruegger surgiu da ampliação das atividades de uma pequena caldeiraria com oficina mecânica e fundição de ferro e bronze no município de Araras, em 1895, de propriedade do suíço Frederico Ruegger, casado com uma ararense. A metalúrgica ocupava um terreno de 5.500 metros quadrados, empregava 60 operários e possuía cinco seçôes: a primeira era responsável pela fabricação de mecanismos completos para fábricas de farinha de mandioca, mecanismos para a produção de macarrão e engenhos de cana, e reparos de qualquer espécie em máquinas e reformas em geral; a segunda seção era a fundição de ferro e bronze, responsável por atender o consumo anual da metalúrgica, de 60 toneladas de ferro; a terceira seção era a de modelagem, onde se criavam os modelos em madeira para a fundição; a quarta seção incluía ferraria, caldeiraria e carpintaria, onde se fabricavam depósitos de água, rodas hidráulicas, carros, carroças, trolleys, carrocerias para veículos a motor etc.; a quinta seção era a serralheria; e ainda havia outra seção, de desenhos, onde os senhores João e Augusto Ruegger criavam os projetos de todos os trabalhos realizados na empresa (ZAMBARDA, 1999, p. 68-69).

A fundição de George Craig e Julio Martins foi fundada em 1895 na cidade de São Paulo, sendo o quarto estabelecimento do gênero fundado por Craig. A fábrica empregava em torno de 100 operários, quase todos estrangeiros, possuindo máquinas para furar, tornear, cortar, limar, prensar e forjar, além de dois tornos patentes, rebites e uma balança de 
$10.000 \mathrm{~kg}$. (BANDEIRA JR., 1901, p. 83). Também em São Paulo foi fundada, em 1892, a Grande Fundição do industrial tenente-coronel Francisco Amaro, discípulo da Grande Fundição Alegria, do Rio de Janeiro. Com o maquinismo a vapor, além da fundição de ferro e bronze a empresa fabricava máquinas inteiras, além de peças para máquinas de toda natureza. Segundo Bandeira Jr., em matéria de mecânica e fundição a empresa rivalizava com as norte-americanas na execução e nos inventos (BANDEIRA JR., 1901, p. 85). A firma Vagnotti \& Cia., fundada em 1900 em São Paulo, operava em 1945 com 149 operários, produzindo acessórios para máquinas têxteis (DEE/DEPC/ SP, 1947, p. 127).

Aparentemente, a maioria das empresas fundadas durante a década de 1890 na indústria de máquinas e equipamentos, além de não ter ligaçóes com o comércio importador, também não surgiu diretamente para atender o setor cafeeiro. Uma exceção é a Fundição Vielhaber, criada em 1895, em Ribeirão Preto pelo Banco Construtor, banco vinculado aos fazendeiros de café, sendo depois vendida a Gustavo Vielhaber, que atendeu aos fazendeiros (BANDEIRA JR., 1901, p. 69). A Metalúrgica Ruegger atendeu ao mercado local e regional de máquinas de farinha de mandioca, macarrão e engenhos de cana. Segundo Zambarda, em 1893 já operava em Araras o Pastifício Padula, fábrica de massas que fornecia ao mercado de Araras e região, distribuindo seus produtos para cidades ligadas pelas estradas de ferro (exceto a Sorocabana). Em 1929, havia em Araras 6 fábricas de aguardente, 3 fábricas de macarrão e 85 fábricas de farinha de mandioca (ZAMBARDA, 1999, p. 67, 68, 72). As empresas de Francisco Amaro, George Craig e Julio Martins e a Vagnotti ofertaram ao mercado de máquinas para as indústrias paulistanas de outros ramos industriais.

A Grande Oficina de Caldeireiro já operava em São Paulo antes de 1870, sob a direção de Virgilio Antonio de Brito, produzindo alambiques e retificadores inventados pelo proprietário, com privilégios de diversas patentes. A empresa produziu ainda caldeiras a vapor para cervejarias, destilarias e tinturarias (BANDEIRA JR., 1901, p. 84).

Assim, algumas das empresas que operavam na indústria de máquinas e equipamentos em 1901 não estavam diretamente ligadas à demanda da cafeicultura, principalmente aquelas situadas na cidade de São Paulo, que já atendiam a um mercado interno industrial incipiente. Fato mais interessante é que algumas empresas que não vendiam máquinas para cafeicultura atuavam em cidades que 
passavam pelo auge cafeeiro quando foram fundadas, como Rio Claro e Araras.

\section{Conclusões}

O presente artigo traçou um panorama da evolução da indústria de máquinas e equipamentos em São Paulo entre 1870 e 1900. Foi realizado um trabalho de organização e sistematização de dados de várias fontes, para melhor compreender o crescimento e desenvolvimento da indústria de máquinas e equipamentos no final do século XIX, atentando para a origem dos empresários no setor. Aqui será feito um balanço dos resultados relatados ao longo do trabalho.

As empresas de máquinas, oficinas mecânicas e fundiçóes em 1873, em sua maioria, faziam parte de um núcleo urbano artesanal. A maioria dos produtores tinha relações com alguma profissão artesanal do local onde estavam situados, como torneiro, carpinteiro, ferreiro, marceneiro, maquinista e outros. Alguns desses produtores eram artesãos de origem germânica, resultado de uma imigração anterior à "imigração em massa" incentivada pela cafeicultura. Havia pouca relação desses produtores com o comércio importador e com fazendas exportadoras. Já em 1891, as empresas da indústria de máquinas no estado de São Paulo apresentaram muitas ligações com o comércio exterior. Muitas das empresas presentes no setor em 1891, além de produzirem algumas máquinas, também às importavam. Essas empresas eram "casas de importação" de propriedade de imigrantes comerciantes, que controlavam o comércio, a distribuição e o financiamento das máquinas importadas. Essa relação das empresas da indústria de máquinas e equipamentos com o comércio importador irá diminuir ao longo da década de 1890.

A produção da indústria mecânica surgiu da necessidade de fornecer assistência técnica para as máquinas que importavam, com o reparo e o fornecimento de peças e de algumas máquinas inteiras. As empresas ligadas a imigrantes comerciantes foram predominantes em 1891, e poucas empresas estavam ligadas diretamente a cafeicultores, como empreendedores. Conseguimos confirmar apenas uma empresa fundada por cafeicultor, apesar de provavelmente existirem mais, mas certamente náo foram predominantes. Ao longo da década de 1890, muitos fazendeiros ligados ao café contribuíram para a expansão e crescimento de firmas de máquinas e equipamentos que abriram o capital e tornaram-se sociedades anônimas no início da década de 1890. A forma de contribuição dos fazendeiros foi através de compra de açôes 
e aquisição do controle de Companhias que principalmente produziam máquinas de beneficiamento de café.

Durante a década de 1890 encontramos ainda a fundação de muitas empresas, aparentemente sem ligação com o comércio exterior (importação e exportação), de imigrantes que possuíam algum conhecimento técnico de mecânica e metalurgia. $\mathrm{Na}$ maioria, essas empresas fundadas entre 1891 e 1901, além de não terem ligações com o comércio importador, também não surgiram para atender diretamente o setor cafeeiro, e sim para atender um mercado específico, local ou regional. As empresas atenderam a necessidade de máquinas para o beneficiamento da mandioca, máquinas para a indústria alimentícia (para fabricar massas), para o beneficiamento e limpeza do arroz, sem contar as de beneficiamento do algodão e da indústria da cana-de-açúcar, principalmente no interior do estado, e da necessidade de máquinas e acessórios para a indústria têxtil, de papel, de papeláo, de borracha e outras indústrias de bens de consumo, principalmente na capital paulista.

Apesar de não ter ligaçóes diretas com o surgimento de algumas empresas de imigrantes mecânicos, o setor cafeeiro incentivou o movimento econômico geral que aumentou as necessidades pa- ra máquinas de outros setores. A maioria das cidades onde localizamos a fundação de empresas que produziam máquinas para outros setores estava ligada economicamente à prosperidade do café. Certamente, o desenvolvimento de economias locais impulsionadas pela economia do café criou demanda e necessidade de outras máquinas. O surgimento de empresas de máquinas que produziam para um mercado local talvez ajude a explicar por que elas nasceram e prosperaram em um período de reduzida proteção efetiva, provavelmente com aumento da concorrência no mercado de máquinas. Essas empresas nasceram, a princípio, para atender uma demanda local e às vezes muito peculiar, ou seja, uma produção com características semi-artesanais, no sentido de que não empregavam uma linha seriada de produção. Outro argumento para justificar o aparecimento de empresas de máquinas é a quantidade variada de tipos de máquinas. Mesmo em mercados menos específicos, como o mercado de máquinas de beneficiamento de café e algodão, havia uma grande variedade de máquinas, com grande variação de preços (ver CANABRAVA, 1984, p. 177-221; LUNÉ, 1985, Anexos, p. 68, 72). 


\section{Referências bibliográficas}

\section{Fontes Primárias}

BANDEIRA JR., A Indústria no Estado de São Paulo em 1901, Sáo Paulo: Tipografia do

Diário Oficial, 1901.

BANAS, G. Anuário Banas: a indústria de máquinas, São Paulo: Editora Banas, 1962.

BRASIL. Tarifa das Alfândegas. Rio de Janeiro: Imprensa Nacional, 1890.

CIA. MC-HARDY. Estatutos da Companhia Mc-Hardy Manufatureira e Importadora, Campinas: Tipografia a Vapor do Livro Azul, 1891.

CIA. MC-HARDY. Relatório que será apresentado à Assembléia Geral dos Acionistas convocada para 28 de fevereiro de 1893,

Campinas: Tipografia

Cardona, 1893.
DEE/DEPC/SP. Catálogo das indústrias do município da capital e interior, 1945, São Paulo: Tipografia Brasil, 1947.

DGE/ MAIC. Recenseamento do Brasil 1920, vol. V. (primeira parte): indústria, Rio de Janeiro. Tipografia de Estatística, 1927.

EXAME. "Os Pioneiros:

Antárctica: 83 anos de dinamismo". Maio de 1974.

FIBGE. O Brasil: suas riquezas naturais e suas indústrias, 3 vol., 1909. Séries estatísticas retrospectivas. Rio de Janeiro: IBGE, 1986

LUNÉ, A. J. B. Almanak da Provincia de São Paulo para 1873. Sáo Paulo: Imprensa Oficial do Estado: Arquivo do Estado, 1985.

SÃo PAUlO. Almanach do Estado de São Paulo para 1891, São Paulo: Cia. Industrial de São Paulo, 1891.

\section{Fontes Secundárias}

BARBOSA, A. S. Empresariado fabril e desenvolvimento econômico: empreendedores, ideologia e capital na indústria do calçado (Franca, 1920-1990). São Paulo: Editora Hucitec/ Fapesp, 2006.

BRANDĀO, M. A. Uma

contribuição ao debate sobre a formação do empresariado industrial no Brasil: de lavoratori na Itália a patrone em Ribeirão Preto $(1890-1930)$. Tese de doutorado, UNESP, Franca, 2009.

BRESSER PEREIRA, L. C

"Empresários, suas origens e as interpretaçōes no Brasil". In: SZMRECSÁNYI, T.; MARANHĀO, R. (orgs.). História de Empresas e Desenvolvimento Econômico. São Paulo: HUCITEC/ABPHE/EDUSP, Imprensa Oficial, 2002.

CAMILLO, E. E. R. Guia histórico da indústria nascente em Campinas (1850-1887), Campinas: Mercado de Letras, Centro de Memória Unicamp, 1998.
CANABRAVA, A. P. O algodão em São Paulo, 1861-1875. São Paulo: T. A. Queiroz, 1984.

CANO, W. "Padrōes diferenciados das principais regióes cafeeiras (1850-1930)". Estudos Econômicos, São Paulo, v. 15, n. 2, p. 241-261, maio-agosto, 1985.

DEAN, W. A industrialização de São Paulo (1880-1945). São Paulo: Difel, 1976.

DEAN, W. As multinacionais: do mercantilismo ao capital internacional. São Paulo: Brasiliense, 1983.

LAGO, L. A. C. ; Almeida, F. L. de; Lima, B. M. F. A indústria brasileira de bens de capital: Origens, situação recente e perspectivas. Rio de Janeiro: FGV/IBRE, 1979.

LEFF, N. H. The Brazilian Capital Goods Industry 1929-1964. Cambridge: Harvard University Press, 1968. 
MADURO JR., P. R. R.; MANCONDES, R. L. "Crédito hipotecário em São Paulo: Evidências para um núcleo urbano em expansão (18651890). Anais Encontro Nacional de Economia (ANPEC). Natal, 2005.

MOOG, V. Bandeirantes e

Pioneiros. Rio de Janeiro:

Globo, 1954.

MOTOYAMA, S. Prelúdio para uma História: ciência e tecnologia no Brasil, São Paulo:

EDUSP, 2004.

SAES, F. "Estradas de Ferro e diversificação da atividade econômica na expansáo cafeeira em São Paulo, 1870-1900". In: SZMRECSÁNYI, T.; LAPA, J. R. A. (2002). História Econômica da Independência e do Império. Sáo Paulo: HUCITEC/ABPHE/EDUSP, Imprensa Oficial, 2002.
SANTOS, F. A. Rio Claro: uma cidade em transformação (18501906). São Paulo: Annablume/ Fapesp, 2002.

SIMONSEN, R. A evolução industrial do Brasil. São Paulo: FIESP, 1939.

STEIN, S. J. Origens e evolução da indústria têxtil no Brasil, 1850-1950. Rio de Janeiro: Campus, 1979.

SUZIGAN, W. Indústria Brasileira. Origem e desenvolvimento. 2. ed., São Paulo: Huicitec/ Unicamp, 2000.

ZAMBARDA, W. I. M. $A$

industrialização de Araras, SP: origens, evolução, características, relaçōes. Rio Claro: Dissertação de mestrado (Unesp), 1999.

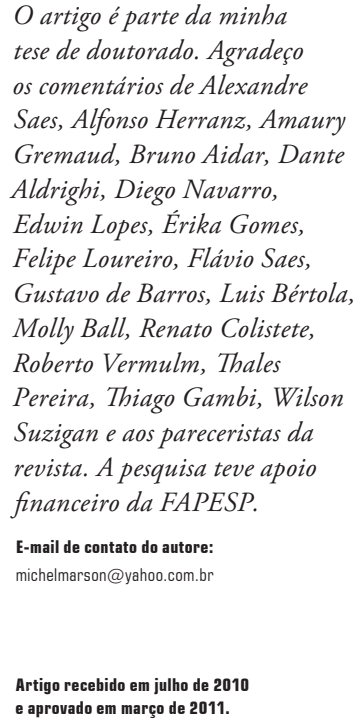


